\title{
L-carnitine has a protective effect on the colonic mucosa during abdominopelvic radiotherapy in rats $^{1}$
}

\author{
Sukru Tas', Omer Faruk Ozkan ${ }^{\mathrm{II}}$, Oztekin Cikman ${ }^{\mathrm{III}}$, Asli Kiraz ${ }^{\mathrm{IV}}$, Yilmaz Akgun', Muammer Karaayvaz ${ }^{\mathrm{VI}}$ \\ DOI: http://dx.doi.org/10.1590/S0102-865020160090000007
}

IAssistant Professor, Department of General Surgery, Faculty of Medicine, Canakkale Onsekiz Mart University, Canakkale, Turkey. Conception and design of the study, technical procedures, manuscript writing, final approval.

IIAssociated Professor, Department of General Surgery, Faculty of Medicine, Canakkale Onsekiz Mart University, Canakkale, Turkey. Scientific and intellectual content of the study, statistical analysis.

IIIAssistant Professor, Department of General Surgery, Faculty of Medicine, Van Yuzuncu Yil University, Van, Turkey. Acquisition of data, manuscript writing.

${ }^{\text {Iv }}$ Specialist Doctor, Department of Medical Microbiology, Faculty of Medicine, Canakkale Onsekiz Mart University, Canakkale, Turkey. Histopathological examinations, manuscript writing, critical revision.

vProfessor, Department of General Surgery, Faculty of Medicine, Canakkale Onsekiz Mart University, Canakkale, Turkey. Analysis and interpretation of data, manuscript preparation, critical revision.

${ }^{\mathrm{VI}}$ Professor, Department of General Surgery, Faculty of Medicine, Canakkale Onsekiz Mart University, Canakkale, Turkey. Conception and design of the study, critical revision.

\section{ABSTRACT}

PURPOSE: To evaluate histopathologically the radioprotective effect of L-carnitine on the colonic mucosa in rats undergoing abdominopelvic irradiation.

METHODS: Thirty-two rats were randomly assigned to four experimental groups: intraperitoneal administration of normal saline (group 1) or L-carnitine (300 mL/kg; group 2), followed in groups 3 and 4, respectively, by one dose of abdominopelvic radiation (20 Gy) 30 min later. Rats were sacrificed 5 days after radiation, and their descending colons were resected for histopathological evaluation of the presence and severity of damage.

RESULTS: Average damage scores did not differ significantly between groups 1 and $2(0.13 \pm 0.35$ and $0.25 \pm 0.46$, respectively); the group 3 score was highest $(10.25 \pm 0.71)$, and the group 4 score $(3.63 \pm 1.41)$ was significantly lower than that of group 3 (both $p=$ 0.0001). Pre-radiation L-carnitine administration significantly reduced mucosal thinning, crypt distortion, reactive atypia, inflammation, cryptitis, and reactive lymph-node hyperplasia (all $p<0.01$ ).

CONCLUSIONS: L-carnitine had a radioprotective effect on rat colonic mucosa. L-carnitine use should be explored for patients with gastrointestinal cancer, who have reduced serum L-carnitine levels.

Key words: Carnitine. Radiation. Colitis. Radiation-Protective Agents. Rats. 


\section{Introduction}

Radiotherapy is used to treat many types of cancer alone (as in esophageal squamous cell carcinoma) or in combination with surgery, chemotherapy, immunotherapy, and/or hormonotherapy ${ }^{1}$. Cells in the gastrointestinal tract are particularly susceptible to damage caused by radiation because they multiply very quickly ${ }^{2}$. The effect of radiotherapy on the gastrointestinal system leads to morbidity and complications that reduce quality of life, posing a financial burden to patients and health systems. These effects also limit the radiation dose applied, which is the most important factor affecting the efficacy of this treatment ${ }^{3}$.

Ionizing radiation has a cytotoxic effect on the intestinal mucosa by increasing the levels of free oxygen radicals ${ }^{4,5}$. Radiation induces damage to and inflammation of the intestinal mucosa during the acute period, and results in the development of radiation-related acute/chronic colitis during the chronic period by generating transmural fibrosis and vascular sclerosis ${ }^{6-8}$. The degree of mucosal change in the early post-radiation period reflects the clinical severity of acute proctitis and the risk of chronic damage ${ }^{9,10}$.

L-carnitine plays a role in the transportation of longchain free fatty acids to mitochondria during beta oxidation. It is essential in the control of carbohydrate-lipid metabolic capacity, the formation of cell membrane structure, cellular vitality, the prevention of free oxygen radical formation, scavenging of free radicals, and protection of cells from peroxidative stress ${ }^{11}$. The body can endogenously synthesize about $10 \%$ of the L-carnitine it requires from lysine and methionine amino acids in the skeletal muscle, heart, liver, kidney, and brain; the remaining amount is generally obtained through diet ${ }^{12,13}$. Experimental models have demonstrated its radioprotective effects in the kidney, lens and cochlea, retina, brain, growing bone, testes, oral mucosa, small intestine and bone marrow ${ }^{14-21}$.

Radiation colitis reduces patients' quality of life due to acute-period symptoms such as nausea, vomiting, abdominal cramping, and bloody or non-bloody diarrhea. Complications that are more difficult to treat, such as anemia, stricture, ulceration, and fistulation, can develop in the chronic period ${ }^{22}$. To our knowledge, no published study has examined the radioprotective effect of L-carnitine on the colonic mucosa. The goal of this study was thus to evaluate the protective effect of L-carnitine after radiation damage to the colonic mucosa of rats. We hypothesized that L-carnitine would have a protective effect against radiation-induced colitis. Radioprotectivity was assessed by histopathological evaluation.

\section{Methods}

This study was performed in the laboratory of Dicle University Health Sciences Research and Application Center, Turkey, with the approval of the university's Laboratory Animals Ethics Committee (no. 2013/25).

Forty-eight female Wistar albino rats weighing 180-220g, obtained from the Laboratory Animal Research Center of Dicle University, were used in this study. All rats were housed in special metal cages at room temperature under stable environmental conditions $\left(21 \pm 2{ }^{\circ} \mathrm{C}, 12\right.$-h light/dark cycle $)$. The rats were given access to normal water and standard food, with no restriction.

The rats were randomly assigned to four experimental groups ( $n=8$ /group): group 1, intraperitoneal (IP) administration of normal saline without radiation; group 2, IP administration of L-carnitine (300 mL/kg [1 g 5 amp.]; Santa Farma Pharmaceutical, Turkey) without radiation; group 3, IP administration of serum saline (100-mL Bioflex bag; Biosel Pharmaceutical Industry and Commerce Inc.), followed $30 \mathrm{~min}$ later by one dose of 20 Gy radiation to the abdominopelvic region; and group 4, IP administration of L-carnitine $(300 \mathrm{~mL} / \mathrm{kg})$, followed $30 \mathrm{~min}$ later by one dose of $20-\mathrm{Gy}$ radiation to the abdominopelvic region. Intraperitoneal injections were made by dividing the abdomen into four quadrants on an imaginary midline and one perpendicular line at the level of the umbilical mark, L-carnitine and sterile saline were administered into the lower-left quadrant by using 1-ml syringes with a $26 \mathrm{G} \mathrm{3/8-inch} \mathrm{needles.} \mathrm{The} \mathrm{selection} \mathrm{of} \mathrm{the} 30$ min interval between intraperitoneal L-carnitine administration and exposure to radiation was based on a previous experimental study ${ }^{14}$.

All rats in groups 3 and 4 were monitored for the development of dehydration and/or diarrhea. Five days after radiation, rats were sacrificed and their descending colons were resected for histopathological evaluation. All experimental procedures (radiation application, sample collection, and euthanasia) were performed under anesthesia, achieved by intramuscular administration of ketamine (Ketalar 500 mg, 90 mg/ kg body weight [BW]; Pfizer) and xylazine (Kepro Xylazine 20, 10 mg/kg BW; Biopharm Veterinary Drugs).

\section{Abdominopelvic irradiation protocol}

After the induction of anesthesia, rats were placed in the supine position with the four extremities secured with flasters. Single radiation doses were applied from a source-abdomen distance of $80 \mathrm{~cm}$ with an ALCYON-II cobalt-60 teletherapy unit (GE Healthcare). 


\section{Tissue collection and histopathological evaluation}

Five days after radiation, laparotomy was performed under anesthesia on rats in all groups to determine the acute effects of abdominopelvic radiation and L-carnitine administration ${ }^{20}$. After cleaning the abdominopelvic region with povidone-iodine, laparotomy was performed by midline incision. The descending colon was dissected and excised. Colonic material was collected and placed in containers with formol and $10 \%$ neutralizing buffer after being washed with saline. Rats were decapitated following material collection. Paraffin-embedded blocks of formol-fixed rectal material were created. Thin $(5-\mu \mathrm{m})$ slices were obtained from the blocks, stained with hematoxylin and eosin, and examined under a light microscope.

Histopathological specimens were evaluated using the method defined previously with technical modification ${ }^{23}$. A blinded pathologist assessed the following 10 parameters: (1) presence of inflammatory infiltrate (inflammation) in the lamina propria, (2) leukocyte infiltration into crypt epithelium (cryptitis), (3) crypt distortion, (4) regenerative (reactive) atypia in epithelial cells, (5) crypt abscess, (6) mucosal ulcer, (7) epithelial degeneration, (8) mucosal edema, (9) mucosal thinning, and (10) reactive lymphnode hyperplasia. All parameters were graded as: 0, no damage; 1, mild damage; 2 , moderate damage; or 3, severe damage. A total damage score (range 0-30) was calculated for each sample, and an average damage score (ADS) was calculated for each group. The same pathologist assessed colonic mucosal thickness under a micrometer microscope with X100 magnification.

\section{Statistical analysis}

Data were analyzed using the Statistical Package for Social Sciences version 11.5, Chicago, IL, USA. Normality of continuous data was determined by the Kolmogorov-Smirnov test. Parametric and non-parametric Mann-Whitney $U$ and KruskalWallis tests were conducted. Data are expressed as means \pm standard deviations. Two-tailed $p$ values $<0.05$ were considered to be statistically significant.

\section{Results}

No complications were noted and no animal died during the experimental process. Histopathological characteristics of all groups are presented in Table 1. The mucosal thickness and ADSs of groups 1 and 2, neither of which was exposed to radiation, did not differ significantly. Group 3 (radiation alone) had the highest ADS and thinnest mucosa, which differed significantly from those of the control (group 1) and group 4 (L-carnitine + radiation; all $p=0.0001)$. Among parameters assessed, group 3 showed significantly more mucosal thinning, crypt distortion (Figure 1), reactive atypia (Figure 2), inflammation (Figure 3), crypt abscess (Figure 4), and reactive lymph-node hyperplasia than group 1 (Table 1). Compared with group 3, L-carnitine administration prior to radiation in group 4 significantly reduced mucosal thinning, crypt distortion, reactive atypia, inflammation, cryptitis, and reactive lymph-node hyperplasia (Table 1).

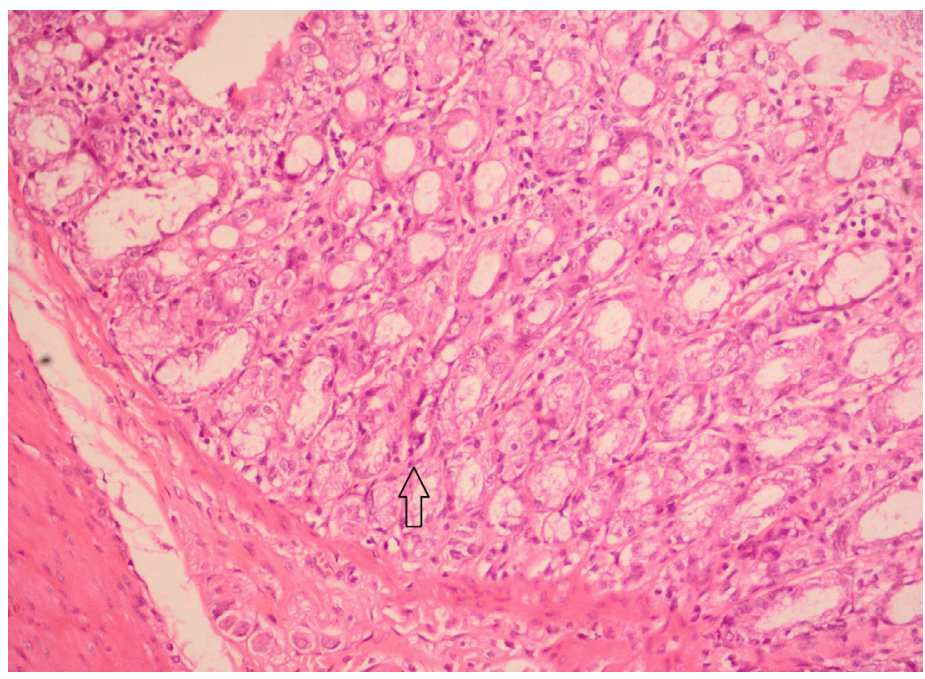

FIGURE 1 - Crypt distortion in the colonic mucosa due to radiation.

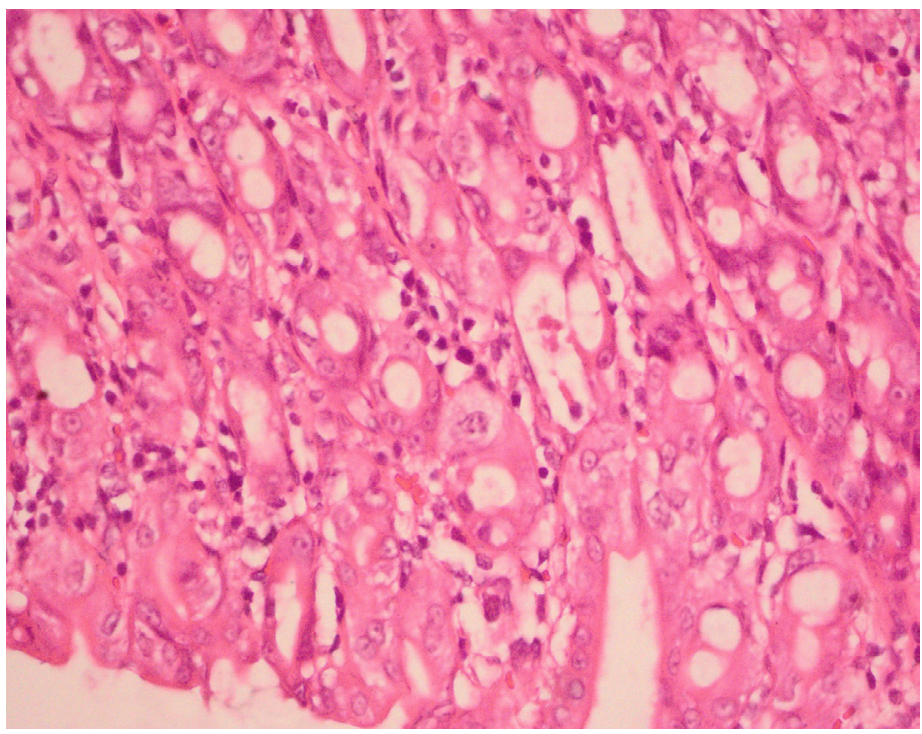

FIGURE 2 - Reactive atypia in epithelial cells caused by radiation. 


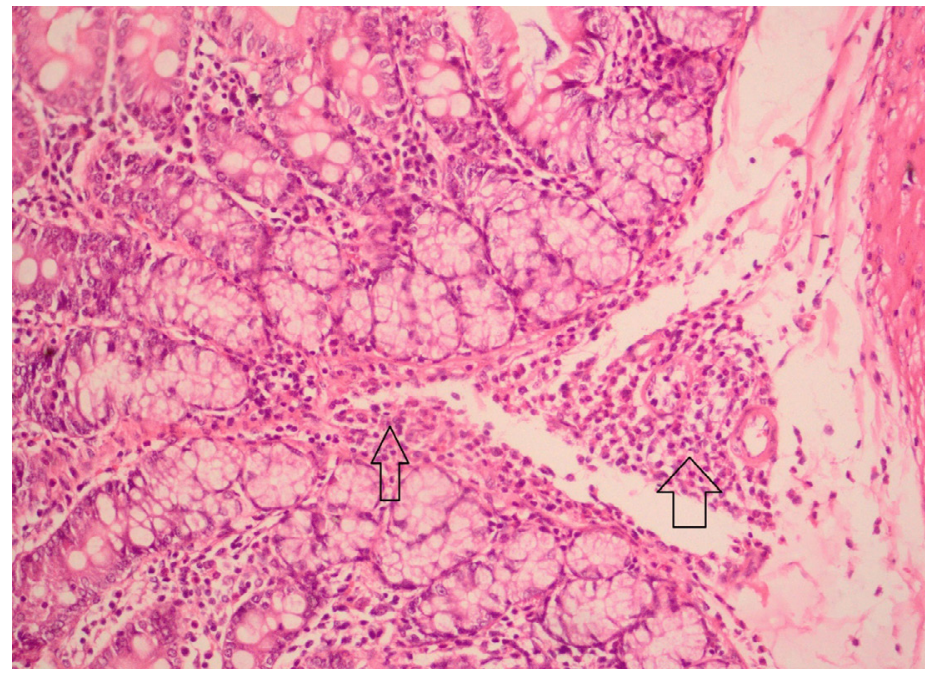

FIGURE 3 - Moderate inflammation (inflammatory infiltrates) in the lamina propria after radiation.

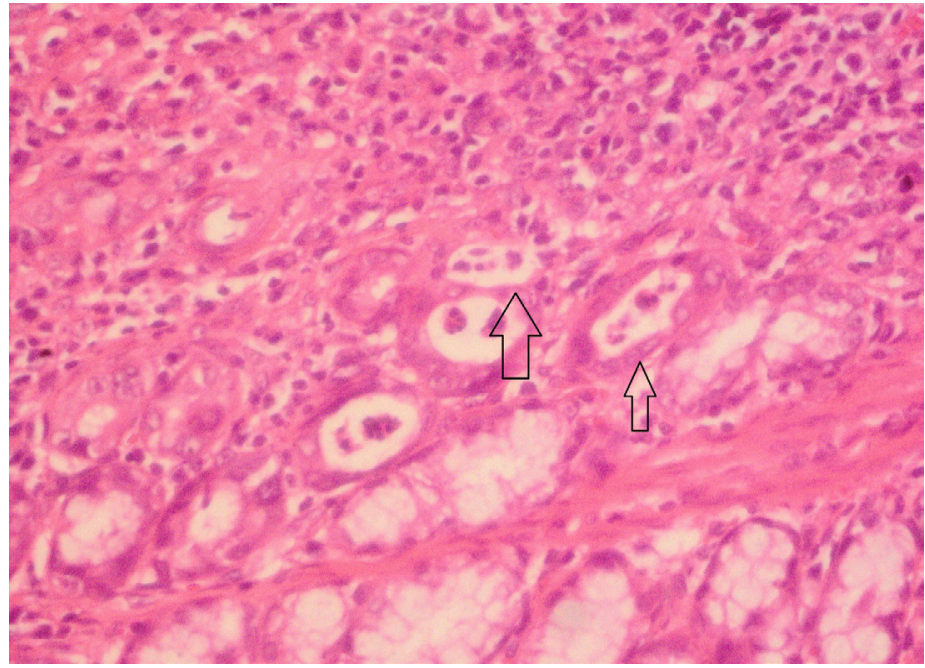

FIGURE 4 - Crypt abscesses characterized by eosinophilic infiltration in the crypt lumen after radiation.

TABLE 1 - Histopathological characteristics of experimental groups.

\begin{tabular}{|c|c|c|c|c|}
\hline Parameter & $\begin{array}{l}\text { Group } 1 \\
\text { (IP saline) }\end{array}$ & $\begin{array}{c}\text { Group } 2 \\
\text { (IP L-carnitine) }\end{array}$ & $\begin{array}{c}\text { Group } 3 \\
\text { (IP saline }+ \text { radiation })\end{array}$ & $\begin{array}{c}\text { Group } 4 \\
\text { (IP L-carnitine }+ \text { radiation) }\end{array}$ \\
\hline Mucosal thinning $(\boldsymbol{\mu m})$ & $0.65 \pm 0.02$ & $0.64 \pm 0.17$ & $0.34 \pm 0.02^{\mathrm{a}}$ & $0.55 \pm 0.02$ \\
\hline Average damage score $(0-30)$ & $0.13 \pm 0.35$ & $0.25 \pm 0.46$ & $10.25 \pm 0.71^{\mathrm{a}}$ & $3.63 \pm 1.41$ \\
\hline Inflammation $(0-3)$ & & & $\mathrm{a}$ & \\
\hline Cryptitis (0-3) & & & $\mathrm{b}$ & \\
\hline Crypt distortion $(0-3)$ & & & $\mathrm{a}$ & \\
\hline Reactive atypia $(0-3)$ & & & $\mathrm{a}$ & \\
\hline Crypt abscess $(0-3)$ & & & $\mathrm{c}$ & \\
\hline Ulceration $(0-3)$ & & & $\mathrm{d}$ & \\
\hline Epithelial degeneration $(0-3)$ & & & d & \\
\hline Edema $(0-3)$ & & & d & \\
\hline Reactive lymph-node hyperplasia (0-3) & & & e & \\
\hline
\end{tabular}

IP, intraperitoneal. ${ }^{\mathrm{a}} p=0.0001 v$ s. groups 1 and $4,{ }^{\mathrm{b}} p=0.005 v$ s. group $4,{ }^{\mathrm{c}} p=0.002 v s$. group $1,{ }^{\mathrm{d}} p=0.001 v s$. groups 1 and $4,{ }^{\mathrm{e}} p>0.005 v s$. group 1,2 and 4 .

\section{Discussion}

Radiation-induced enteropathy is a well-known side effect of radiotherapy. Only $10 \%$ of patients treated with pelvic radiotherapy show no side effects ${ }^{24}$. Radiation colitis significantly reduces patients' quality of life in physical, psychological, and social terms ${ }^{25}$. In $5-15 \%$ of patients, treatment is ceased or altered due to colonic mucosal damage caused by abdominopelvic radiotherapy ${ }^{26}$. In this study, we found that radiation alone caused significant damage, as indicated by total damage and several individual parameter scores, compared with experimental groups not exposed to radiation. Two strategies to reduce this damage can be employed: the technical strategy of reducing the dose or exposed area, and the biological strategy of using substances that prevent tissue damage or cellular response to ionizing radiation ${ }^{27}$.
Serum L-carnitine levels are reduced in patients with gastrointestinal cancer due to compromised nutrition and deregulation of lipid and carbohydrate metabolism ${ }^{28}$. An intact L-carnitine system, with adequate amounts of L-carnitine, carnitine transferase enzymes, and carnitine derivatives, is necessary for glucose and lipid metabolism in cells and is an indication of cellular resistance to toxic effects. The radioprotectivity of L-carnitine is derived from its antioxidant effects. Oxidative stress induced by free radicals has been shown to significantly reduce DNA damage and augmentation of the tumor necrosis factor- $\alpha$ level ${ }^{29-31}$. L-carnitine support has been shown to reduce radiationrelated fatigue syndrome in patients, but its radioprotective effect on the colonic mucosa has not yet been demonstrated ${ }^{32}$.

The search for ideal radioprotective agents has continued over a long period of time ${ }^{33}$. Currently only two radioprotective 
compounds have US FDA approval, amifostine and palifermin. However, several agents such as free radical scavengers have been reported to show therapeutic promise ${ }^{34}$. A search of the PubMed database revealed no study published in English on the effect of systemic L-carnitine administration on the colonic mucosa during abdominopelvic irradiation. In this study, L-carnitine significantly reduced the total histopathological damage caused by radiation to the colonic mucosa in rats. L-carnitine thus had a preventive effect in terms of radiation colitis in this model. Kouvaris et al. ${ }^{35}$ demonstrated the radioprotective effect of the prodrug amifostine on the colonic mucosa. However, patients' blood pressure and pulse must be monitored during amifostine administration, and this product has well-known side effects, such as nausea, vomiting, a negative effect on serum calcium metabolism, a narrow nontoxic dose range, and high cost. In contrast, L-carnitine has few side effects, a wide dose range, and a longer half-life; its administration is also simple. Sezen et al. ${ }^{16}$ reported that L-carnitine had radioprotective effects on the brain and retina. Caloglu et al. ${ }^{20}$ investigated the efficacy of LC in the prevention of radiation-induced acute small intestine damage and showed partial effectiveness. Our study has some limitations. First, the radiationinduced colonic mucosal damage was induced by single-dose irradiation, which may be different from routine abdominopelvic clinical applications. Second, only a histopathological model was used for the evaluation process. Combining different models such as evaluating markers of oxidative stress in intestinal tissue with histopathological examination may be necessary to determine the radioprotective mechanisms of L-carnitine.

\section{Conclusions}

L-carnitine use at the dose recommended for wound healing provided benefits to the colonic mucosa in terms of radiation colitis, with few side effects and a wide nontoxic dose range. These effects might be critical in patients with primary gastrointestinal tract cancer, who have reduced serum levels of L-carnitine. Use of L-carnitine shows promise for patients undergoing radiation therapy. We think that further prospective, randomized, clinical research is required to identify the mechanism underlying the effects of L-carnitine in patients undergoing radiation therapy.

\section{References}

1. Zagar TM, Willett CG, Czito BG. Intensity-modulated radiation therapy for anal cancer: toxicity versus outcomes. Oncology. 2010;24(9):815-23. PMID: 20923035.
2. Bounous G, LeBel E, Shuster J, Gold P, Tahan WT, Bastin E. Dietary protection during radiation therapy. Strahlentherapie. 1975;149(5):476-83. PMID: 807995.

3. Turini M, Redaelli A, Gramegna P, Radice D. Quality of life and economic considerations in the management of prostate cancer. Pharmacoeconomics. 2003;21(8):527-41. PMID: 12751912.

4. Potten CS. Radiation, the ideal cytotoxic agent for studying the cell biology of tissues such as the small intestine. Radiat Res. 2004;161(2):123-36. PMID: 14731078 .

5. Berthrong M. Pathologic changes secondary to radiation. World J Surg. 1986;10(2):155-70. PMID: 3705602.

6. Andreyev J. Gastrointestinal complications of pelvic radiotherapy: are they of any importance? Gut. 2005;54(8):1051-4. doi: 10.1136/ gut.2004.062596.

7. Freund U, Schölmerich J, Siems H, Kluge F, Schafer HE, Wannenmacher M. Unwanted side-effects in using mesalazine (5-aminosalicylic acid) during radiotherapy. Strahlenther Onkol. 1987;163(10):678-80. PMID: 3313776.

8. Luna-Perez P, Rodriguez-Ramirez SE. Formalin instillation for refractory radiation-induced hemorrhagic proctitis. J Surg Oncol. 2002;80(1):41-4. PMID: 11967906.

9. Sher ME, Bauer J. Radiation-induced enteropathy. Am J Gastroenterol. 1990;85(2):121-8. PMID: 2301333.

10. Johnson RJ, Carrington BM. Pelvic radiation disease. Clin Radiol. 1992;45(1):4-12. doi: 10.1016/S0009-9260(05)81458-8.

11. Mansour HH. Protective role of carnitine ester against radiationinduced oxidative stress in rats. Pharmacol Res. 2006;54(3):165-71. PMID: 16757176.

12. Vaz FM, Wanders RJ. Carnitine biosynthesis in mammals. Biochem J. 2002;361(3):417-29. PMID: 11802770.

13. Hoppel C. The physiological role of carnitine. In: Ferrari R, Dimauro S, Sherwood G (eds). L-carnitine and its role in medicine: from function to therapy. London: Academic Press; 1992. p.5-19.

14. Caloglu M, Yurut-Caloglu V, Durmus-Altun G, Oz-Puyan F, Ustun F, Cosar-Alas R, Saynak M, Parlar S, Turan FN, Uzal C. Histopathological and scintigraphic comparisons of the protective effects of L-carnitine and amifostine against radiation-induced late renal toxicity in rats. Clin Exp Pharmacol Physiol. 2009;36(56):523-30. PMID: 19673935.

15. Kocer I, Taysi S, Ertekin MV, Karslioglu I, Gepdiremen A, Sezen O, Serifoglu K. The effect of L-carnitine in the prevention of ionizing radiation-induced cataracts: a rat model. Graefes Arch Clin Exp Ophthalmol. 2007;245(4):588-94. PMID: 16915402.

16. Sezen O, Ertekin MV, Demircan B, Karslioğlu I, Erdoğan F, Koçer I, Calik I, Gepdiremen A. Vitamin E and L-carnitine, separately or in combination, in the prevention of radiation-induced brain and retinal damages. Neurosurg Rev. 2008;31(2):205-13. PMID: 18259790.

17. Yurut-Caloglu V, Durmus-Altun G, Caloglu M, Usta U, Saynak M, Uzal C, Cosar-Alas R, Kocak Z. Comparison of protective effects of L-carnitine and amifostine on radiation-induced toxicity to growing bone: histopathology and scintigraphy findings. Asian Pac J Cancer Prev. 2010;11(3):661-7. PMID: 21039033.

18. Ahmed MM, Ibrahim ZS, Alkafafy M, El-Shazly SA. L-carnitine protects against dysfunction caused by gamma irradiation in mice. Acta Histochem. 2014;116(6):1046-55. PMID: 24925768.

19. Ucuncu H, Ertekin MV, Yoruk O, Sezen O, Ozkan A, Erdoğan F, Kiziltunc A, Gündoğdu C. Vitamin E and L-carnitine, separately or in combination, in the prevention of radiation-induced oral mucositis and myelosuppression: a controlled study in a rat model. J Radiat Res. 2006;47(1):91-102. PMID: 16571922.

20. Caloglu M, Caloglu VY, Yalta T, Yalcin O, Uzal C. The histopathological comparison of L-carnitine with amifostine for protective efficacy on radiation-induced acute small intestinal toxicity. J Cancer Res Ther. 2012;8(2):260-5. PMID: 22842372. 
Tas S et al.

21. Alzahrani HAS. Protective effect of L-carnitine against acrylamideinduced DNA damage in somatic and germ cells of mice. Saudi J Biol Sci. 2011;18(1):29-36. doi: 10.1016/j.sjbs.2010.07.004.

22. Leiper K, Morris AI. Treatment of radiation proctitis. Clin Oncol. 2007;19(9):724-9. doi: 10.1016/j.clon.2007.07.008.

23. Howarth GS, Fraser R, Frisby CL, Schirmer MB, Yeoh EK. Effects of insulin-like growth factor-I administration on radiation enteritis in rats. Scand J Gastroenterol. 1997;32(11):1118-24. PMID: 9399392.

24. Lam MCW, Parliament M, Wong CKW. Argon plasma coagulation for the treatment of hemorrhagic radiation colitis. Case Rep Gastroenterol. 2012;6(2):446-51. doi: 10.1159/000339462.

25. Abayomi J, Kirwan J, Hackett A, Bagnall G. A study to investigate women's experiences of radiation enteritis following radiotherapy for cervical cancer. J Hum Nutr Diet. 2005;18(5):353-63. PMID: 16150131 .

26. Hauer-Jensen M, Fink LM, Wang J. Radiation injury and the protein C pathway. Crit Care Med. 2004;32(5):325-30. PMID: 15118539.

27. Shadad AK, Sullivan FJ, Martin JD, Egan LJ. Gastrointestinal radiation injury: prevention and treatment. World J Gastroenterol. 2013;19(2):199-208. doi: 10.3748/wjg.v19.i2.199.

28. Malaguarnera M, Risino C, Gargante MP, Oreste G, Barone G, Tomasello AV, Costanzo M, Cannizzaro MA. Decrease of serum carnitine levels in patients with or without gastrointestinal cancer cachexia. World J Gastroenterol. 2006;12(28):4541-5. PMID: 16874868 .

29. Rizzo AM, Berselli P, Zava S, Montorfano G, Negroni M, Corsetto $\mathrm{P}$, Berra B. Endogenous antioxidants and radical scavengers. Adv Exp Med Biol. 2010;698:52-67. PMID: 21520703.

30. Gulcin I. Antioxidant and antiradical activities of L-carnitine. Life Sci. 2006;78(8):803-11. PMID: 16253281.

31. Calo LA, Pagnin E, Davis PA, Semplicini A, Nicolai R, Calvani $\mathrm{M}$, Pessina AC. Antioxidant effect of L-carnitine and its short chain esters: relevance for the protection from oxidative stress related cardiovascular damage. Int J Cardiol. 2006;107(1):54-60. PMID: 16337498
32. Graziano F, Bisonni R, Catalano V, Silva R, Rovidati S, Mencarini E, Ferraro B, Canestrari F, Baldelli AM, De Gaetano A, Giordani P, Testa E, Lai V. Potential role of levocarnitine supplementation for the treatment of chemotherapy-induced fatigue in non-anaemic cancer patients. Br J Cancer. 2002;86(12):1854-7. PMID: 12085175.

33. Gudkov SV, Popova NR, Bruskov VI. Radioprotectors: History, trends and prospects. Biofizika. 2015;60(4):801-11. PMID: 26394481.

34. Johnke RM, Sattler JA, Allison RR. Radioprotective agents for radiation therapy: future trends. Future Oncol. 2014;10(15): 234557. PMID: 25525844.

35. Kouvaris JR, Kouloulias VE, Vlahos LJ. Amifostine: the first selective-target and broad-spectrum radioprotector. Oncologist. 2007;12(6):738-47. PMID: 17602063.

\section{Correspondence:}

Sukru Tas

Department of General Surgery, Faculty of Medicine

Canakkale Onsekiz Mart University, Floor 2, 17100

Canakkale, Turkey

Phone: +90 5303037992

Fax: +902862180516

sukrutas@comu.edu.tr

Received: May 22, 2016

Review: July 20, 2016

Accepted: Aug 23, 2016

Conflict of interest: none

Financial ssource: none

${ }^{1}$ Research performed at Dicle University Health Sciences Research and Application Center (DUSAM) Laboratory, Diyarbakır, Turkey. 